\title{
Thermal and Flammability Properties of Kenaf/Recycled Carbon Filled with Cardanol Hybrid Composites
}

\author{
Zahra Dashtizadeh $\mathbb{D D}^{1,2}$ K. Abdan $\mathbb{D}^{1},{ }^{3}$ M. Jawaid $\left(\mathbb{D},{ }^{1}\right.$ and Masoud Dashtizadeh ${ }^{4}$ \\ ${ }^{1}$ Institute of Tropical Forestry and Forest Products, University Putra Malaysia, Malaysia \\ ${ }^{2}$ Department of Chemical Engineering, Tarbiat-Modarres University, Tehran, Iran \\ ${ }^{3}$ Department of Biological and Agricultural Engineering, University Putra Malaysia, Malaysia \\ ${ }^{4}$ Department of Civil Engineering, Azad Islamic University of Gorgan, Iran
}

Correspondence should be addressed to Zahra Dashtizadeh; zdashtizadeh@gmail.com

Received 11 April 2019; Revised 17 June 2019; Accepted 14 August 2019; Published 5 September 2019

Academic Editor: Cornelia Vasile

Copyright (c) 2019 Zahra Dashtizadeh et al. This is an open access article distributed under the Creative Commons Attribution License, which permits unrestricted use, distribution, and reproduction in any medium, provided the original work is properly cited.

\begin{abstract}
In this paper, hybrid composites were fabricated by using kenaf and recycled carbon with a cashew nut shell liquid (CNSL) derivative known as cardanol as the matrix by a compression molding technique. In this work, we look for the effect of recycled carbon weight loading $(15 \%, 25 \%$, and $35 \%)$ on the thermal properties of kenaf/cardanol composites while maintaining the total fiber loading of $50 \mathrm{wt} \%$. TGA, DSC, DMA, and flammability UL $90 \mathrm{HB}$ properties of the specimens were studied. The results indicate that cardanol improved the thermal stability of kenaf and hybridization with recycled carbon also further improved the thermal stability of the specimens. The flammability UL $90 \mathrm{HB}$ test determines the flame retardancy property of all specimens.
\end{abstract}

\section{Introduction}

High-end industries use high-quality materials such as phenolic compounds which are materials with phenolic content that are hazardous pollutants with low degradability [1]. Therefore, there is a huge need to substitute materials made from phenolic compounds with biodegradable, nontoxic materials to fulfill environmental and sustainability issues.

Currently, different state-of-the-art industries mostly use carbon and glass fibers which are nonbiodegradable and heavy as compared to natural fibers. The heavy weight of glass or carbon fiber composites increases fuel consumption [2]. Besides, the synthetic fibers are harmful to human health and create economic and environmental issues [3]. Nevertheless, recycling the valuable carbon fiber has gained great attention around the world because of environmental issues, shortage of landfills, and the low regulation for waste products $[4,5]$. Besides, the production of virgin carbon fiber is much more energy consuming than producing steel, from $286 \mathrm{MJ} / \mathrm{kg}$ for carbon fiber to $33 \mathrm{MJ} / \mathrm{kg}$ for steel [6].
Due to the increment in the price of petrol-/chemicalbased resins and also due to environmental issues, natural resins have been studied lately. Cardanol, which is a biophenolic resin derived from cashew nut shell liquid (CNSL), is abundant in tropical environments such as in India and its cheap price is a great benefit [7]. However, very few studies have been performed on cardanol as a matrix for composites, as well as on characterizing its curing parameters such as curing temperature and time.

Cardanol, having biodegradability, high thermal stability, and fire retardant properties, is an attractive bioresin for composite structures. Up to date, cardanol has been used mostly to produce different types of thermoset polymer resins for use in brake components [7] and surface coatings [8].

Substituting synthetic fibers with natural fibers or combining natural fibers with synthetics fibers $[9,10]$ has been a motivation for material scientists to develop natural fiber composites that would enhance the lifestyle of people globally with renewable and sustainable products. From the economic aspect, due to the increment of energy cost, the final 
TABLE 1: Hybrid composite formulation.

\begin{tabular}{lcccc}
\hline Specimen & Kenaf (wt\%) & Carbon (wt $\%)$ & Cardanol (wt $\%)$ & Description \\
\hline $100 \mathrm{CL}$ & 0 & 0 & 100 & $100 \%$ cardanol, control sample \\
$50 \mathrm{~K}$ & 50 & 0 & 50 & $50 \%$ kenaf $/ 50 \%$ cardanol, control sample \\
$50 \mathrm{~K} 50 \mathrm{C}$ & 25 & 25 & 50 & $25 \%$ kenaf $/ 25 \% \mathrm{carbon} / 50 \% \mathrm{cardanol}$ \\
$70 \mathrm{~K} 30 \mathrm{C}$ & 35 & 15 & 50 & $35 \%$ kenaf $/ 15 \% \mathrm{carbon} / 50 \% \mathrm{cardanol}$ \\
$30 \mathrm{~K} 70 \mathrm{C}$ & 15 & 35 & 50 & $15 \%$ kenaf $/ 35 \% \mathrm{carbon} / 50 \% \mathrm{cardanol}$ \\
\hline
\end{tabular}

cost of products with good properties is increasing [11, 12]; thus, there is the need for high-performance materials with low cost. Therefore, it is more economical to use natural hybrid composites since decreased fuel consumption results in significant cost reduction. In summary, the hybridization can balance the cost and performance of the biocomposites. In this research, a hybrid product is investigated with two types of fibers and one resin. The fibers are the kenaf short bast fiber (KSBF) and the recycled carbon short fiber (RCSF), while the resin is cardanol (CL). This hybridization could significantly encourage industrial applications.

A phenolic resin has great thermal stability, dimensional stability, chemical resistance, and load-bearing capability at elevated temperatures [13]. Phenolic resins have a wide range of applications such as in commodity and construction materials as well as in high technology industries such as in the aerospace industry. This wide range of applications is due to the favorable characteristics of the phenolic resin such as high solvent resistance, flame resistance, and low smoke generation [14].

Phenolic resins create char when they are subjected to a flame or fire. The char production with low thermal conductivity protects the surrounding materials. This is also the reason for its application in products that are flame resistant, fire retardant, and smoke generation resistant. Besides, the low thermal conductivity of the phenolic resin makes it an attractive material for toasters and knobs for kitchen appliances. In addition, the high electric-resistant property of the phenolic resin promotes its application in electrical switches and circuit breakers. Since phenolic resins are abrasive in nature, their machining is difficult, and therefore, they are molded to the desired shape $[15,16]$.

The cashew nut shell phenolic oil benefits from an aromatic structure; therefore, the six-member carbon ring results in chemical- and heat-resistant properties. This product does not affect the food industry because the cashew nut shell is a waste product and is nonedible. Novolac resins derived from CNSL and used as an epoxy hardener can be used with different manufacturing processes such as pultrusion, infusion, resin transfer molding (RTM), and prepreg [17].

Based on what has been mentioned above, the hybridization of the recycled carbon fiber and the kenaf bast short fiber has a great opportunity for wealth creation and enhancement of life quality, since both components are environmentally friendly. Although recycling the carbon fiber might seem expensive, when considering the hybridization with kenaf fiber which is cheap and renewable, it is a promising method for the future of new industries to produce the hybrid bio- composites made up of natural fibers (kenaf) and recycled carbon fibers.

\section{Materials and Method}

2.1. Materials. Kenaf fiber was provided by the Laboratory of Biocomposites, Institute of Tropical Forestry and Forest Products (INTROP), University Putra Malaysia (UPM) in bundle form which had to be cleaned and combed properly before use. The density of the kenaf fiber is $1.16-1.4 \mathrm{~g} / \mathrm{m}^{3}$, and the diameter varies between $68 \mu \mathrm{m}$ and $120 \mu \mathrm{m}$. For the chemical treatment of kenaf fibers, $\mathrm{NaOH}$ was used which was purchased from Megwena Synergy Sdn. Bhd. The matrix of the composite is cardanol, which was purchased from Chemovate, India in particle form with a diameter of 75 $\mu \mathrm{m}$. Recycled carbon was purchased from Easy Composites Ltd., UK. Its density was approximately $1.8 \mathrm{~g} / \mathrm{cm}^{3}$, and its length was $\leq 100 \mu \mathrm{m}$.

2.2. Fabrication of Composites. Kenaf fibers were physically cleaned, combed, and treated with $2 \% \mathrm{NaOH}$ for $4 \mathrm{hrs}$. Then, the fibers were washed with tap water until the $\mathrm{pH}$ of the fibers reached neutral. After that, the fibers were put in an ambient environment before putting in the oven at $100^{\circ} \mathrm{C}$ for $15 \mathrm{hrs}$ to dry completely. Then, the fibers were ground with a grinding machine to reach the desired length of $90 \mu \mathrm{m}<L<120 \mu \mathrm{m}$ for a more homogenous mixing process with other components.

Then, the hybrid composites were fabricated by mixing the components with a mechanical mixer and then putting the components into the mold for compression molding at $160^{\circ} \mathrm{C}$ and 1 bar for $20 \mathrm{~min}$ followed by $1 \mathrm{hr}$ of postcuring at $160^{\circ} \mathrm{C}$ and 0 bar. The composite formulation is tabulated in Table 1, and the whole process is shown in Figure 1.

2.3. Characterization. Thermal characterizations of the specimens were conducted by thermogravimetric analysis (TGA) and differential scanning calorimetric analysis (DSC), while dynamic mechanical analysis (DMA) was also determined. Besides, the flammability property of the specimen was determined by flammability UL $90 \mathrm{HB}$.

Thermogravimetric analysis (TGA) was performed using the Q500 TGA model of TA Instruments. The temperature range was from $30^{\circ} \mathrm{C}$ to $900^{\circ} \mathrm{C}$ with a rate of $10^{\circ} \mathrm{C} / \mathrm{min}$. The behavior of the specimens with the increment of the temperature was studied to determine the different decomposition stages for each specimen. TGA also provides the information of the contribution of each component in the composite on 


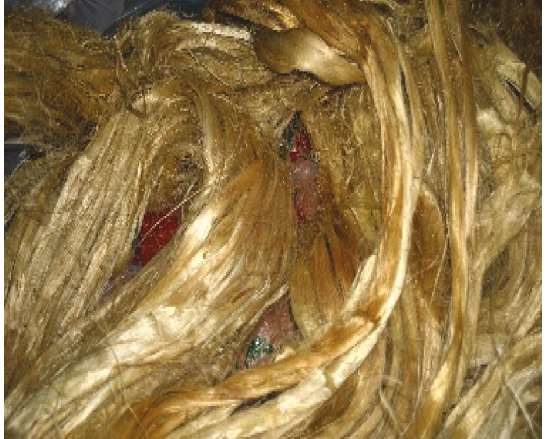

(a) Bundle of dirty kenaf

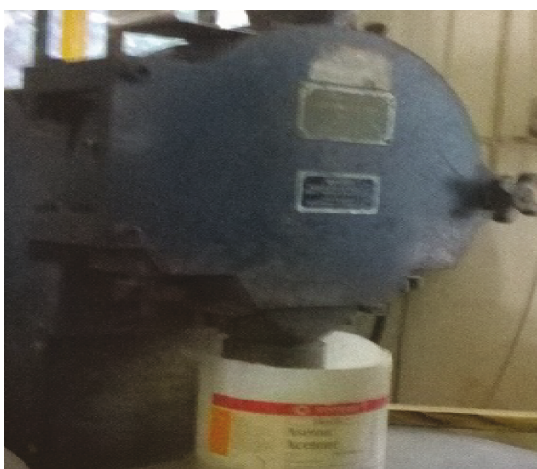

(d) Grinding kenaf fibers

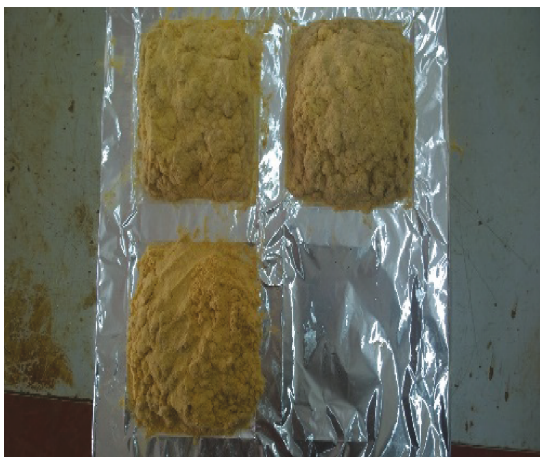

(g) Putting the mixture into the mold

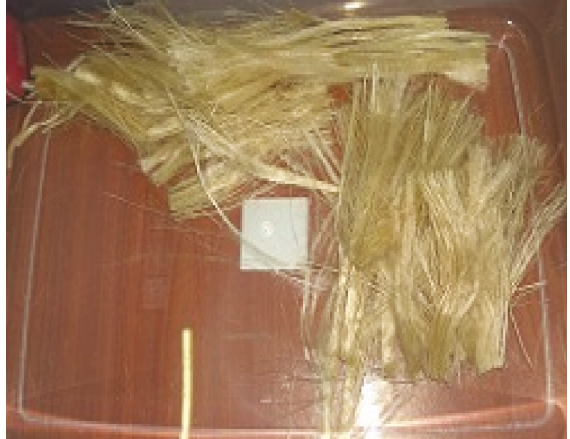

(b) Clean and tidy kenaf fibers

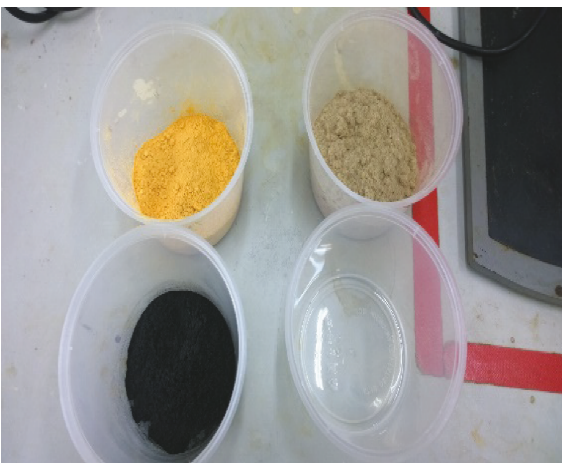

(e) Kenaf, recycled carbon, and cardanol prepared for mixing

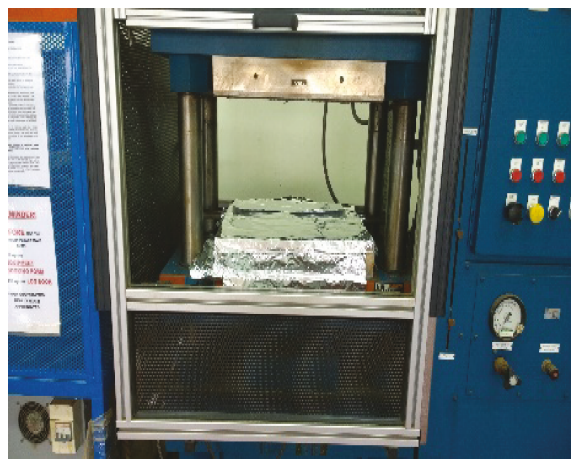

(h) Compression molding

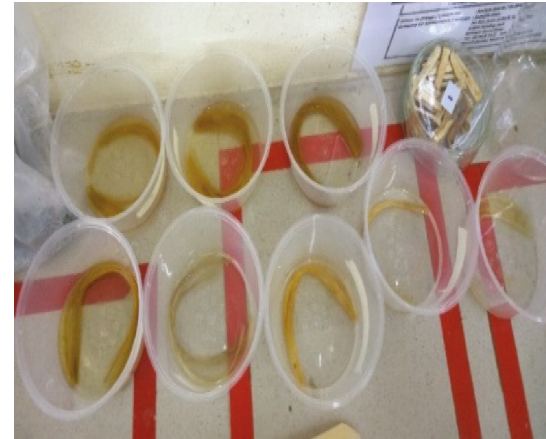

(c) $\mathrm{NaOH}$ treatment

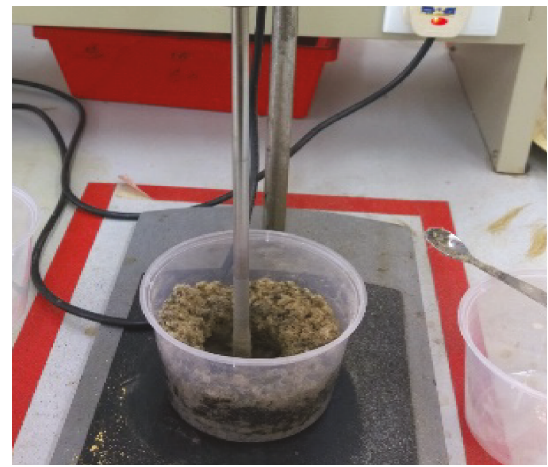

(f) Mixing the components with a mechanical mixer

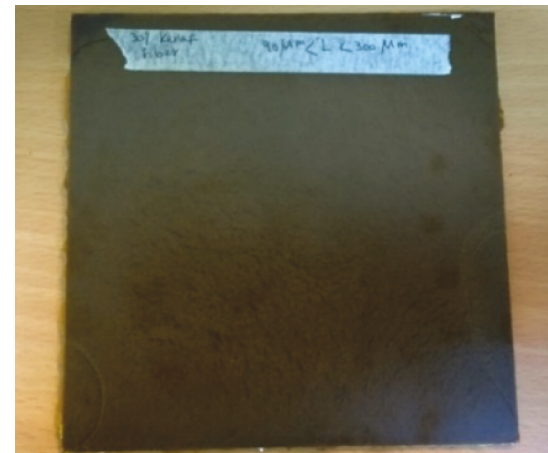

(i) Final composite

FIGURE 1: The procedure of the fabrication of the hybrid composite.

the decomposition temperatures. The effect of fiber volume fraction on the decomposition stages was studied.

Differential scanning calorimetry (DSC) of the specimens was studied using a DSC Q20 machine, using a range of temperature from $30^{\circ} \mathrm{C}$ to $280^{\circ} \mathrm{C}$ with the increment rate of $10^{\circ} \mathrm{C} / \mathrm{min}$. Dynamic mechanical analysis (DMA) of the specimens was conducted to study the viscoelastic behavior of the specimen with consideration of the effect of hybridization. The ASTM D4065-01 was followed for the DMA test of the specimens. The size of the specimens was $35 \times 12 \times 3 \mathrm{~mm}^{3}$. The DMA Q800 machine located at INTROP was used to perform this test.

The flammability UL $90 \mathrm{HB}$ was performed on the specimens according to the ASTM D3801 standard. In order to do the test, the specimens needed to go under pretreatment for $48 \mathrm{~h}$ at $23^{\circ} \mathrm{C}$ with a humidity of $50 \%$. After preparing the specimen, with the help of a boss clamp, the specimen is fixed in a horizontal position, then the flame is applied from a Bunsen burner. A flame with a length of $20 \mathrm{~mm}$ and an angle of $45^{\circ}$ was applied to one end of the specimen with a thickness of $3 \mathrm{~mm}$ for testing. The burning rate was then calculated as follows:

$$
\text { Burning rate }=\frac{\text { length of burning }(\mathrm{mm})}{\text { duration of burning }(\mathrm{s})} \text {. }
$$

The specimen with a length of $125 \mathrm{~mm}$ was divided into three parts as shown in Figure 2. The flame was applied for $30 \mathrm{~s}$, and then the time of burning until the specimen was extinguished after removing the flame was measured. In addition, the length of the burning area was measured. If 


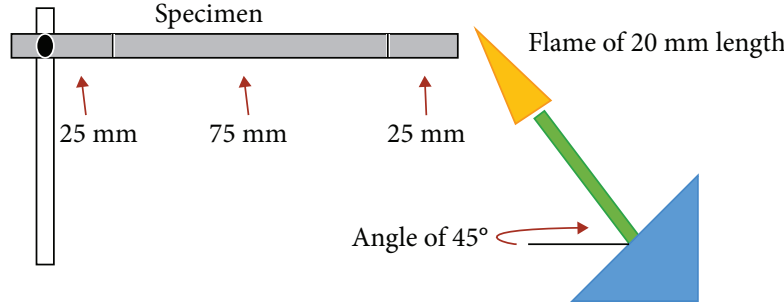

Figure 2: Flammability UL 90 HB test schematic.

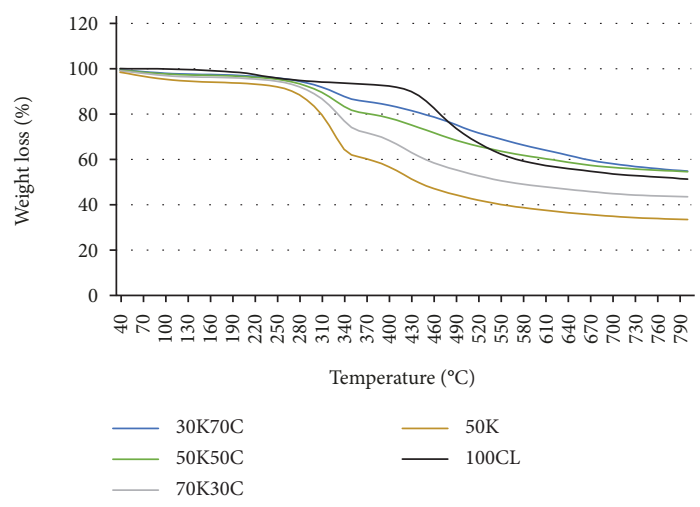

FIgURE 3: TGA of the hybrid composites.

the flame reaches the first mark on the specimen (length of $25 \mathrm{~mm}$ ), then the flame application should be removed from the specimen. The burning rate is then calculated. The test was repeated for 5 samples.

\section{Results and Discussion}

3.1. Thermogravimetric Analysis (TGA). Figure 3 illustrates TGA of the hybrid composites with the control specimens (50 K and 100CL), and Table 2 shows the degradation temperature for each step as well as weight loss and residue percentage. Based on Table 2, the first degradation occurred for kenaf fibers, followed by cardanol in the second degradation, then finally carbon degraded in the third step. The weight loss percentage also determined the above assumption.

Figure 3 shows that the evaporation of the moisture content in hybrid composites occurred up to the temperature of $150^{\circ} \mathrm{C}$, which showed that with a slight inclined line, the natural lignocellulose decomposed at around $350^{\circ} \mathrm{C}$. Finally, carbon was decomposed later at two stages, one at around $420^{\circ} \mathrm{C} \sim 500^{\circ} \mathrm{C}$ and the second decomposition was at around $630^{\circ} \mathrm{C}$. It was observed that the degradation of cardanol occurred at the higher temperature of $430.09^{\circ} \mathrm{C}$.

From Table 2, it can be observed that the degradation of cardanol which occurs in one stage happens at $430.09^{\circ} \mathrm{C}$, and it is much higher than the initial degradation of all other specimens. Hybridization with the recycled carbon fiber did not significantly influence the initial degradation temperature of the specimens; however, for second degradation stage, the recycled carbon fiber loading of $70 \mathrm{wt} \%$ enhanced the degradation temperature by $42.8^{\circ} \mathrm{C}$. It is observed that the temperature of second degradation stage increased with the increment of recycled carbon fiber loading. Figure 3 indicates that the presence of recycled carbon increased the thermal stability because the samples with $70 \mathrm{wt} \%$ carbon illustrated a higher thermal stability and lost less weight with the increment of the temperature. According to Figure 3, 30K70C showed higher thermal stability than $50 \mathrm{~K} 50 \mathrm{C}$, which is higher than $70 \mathrm{~K} 30 \mathrm{C}$; to conclude, the increment of recycled carbon content results in an increase of thermal stability.

Interestingly, while there are only two stages of thermal degradation for the kenaf/cardanol biocomposite, for kenaf/recycled carbon/cardanol hybrid composites, there are three stages of thermal degradation at which the effect of the recycled carbon fiber is shown at the third stage. Meanwhile, the TGA graphs of all of the hybrid specimens were considerably higher than that of kenaf/cardanol biocomposites $(50 \mathrm{~K})$. This is because the carbon fiber is a more thermally stable component compared to kenaf fiber, which is why the curves of the hybrid composites shifted towards the higher temperature while the weight loss percentage decreased; this means that the hybrid composites lost less weight at a higher temperature range during pyrolysis. Besides, it was previously shown that the enhanced thermal stability is also caused by the carbon fiber which acts as an obstacle for the resin movement during thermal degradation [18].

Figure 3 also illustrates that the thermal stability of cardanol was higher than the hybrid composites up to $500^{\circ} \mathrm{C}$, after which the degradation of cardanol sped up. Previously, it was reported that the initial temperature for carbon fiber degradation was $585^{\circ} \mathrm{C}$ [19], while it was reported that the degradation of the carbon-fiber-reinforced phenolic resin occurred at the temperature range of $200^{\circ} \mathrm{C}$ to $900^{\circ} \mathrm{C}$ [20].

3.2. Differential Scanning Calorimetry. DSC of the hybrid composites is presented in Figure 4, and the melting point and decomposition peak temperatures are given in Table 3 . From Figure 4, it can be observed that there is a shift towards a higher temperature for the decomposition of the hybrid composites, indicating that the presence of the recycled carbon fiber improved the thermal stability of the kenaf/cardanol biocomposites. Besides, the hybrid composites melted at a higher temperature. The absence of an exothermic peak determined the full cure of the cardanol, while the high endothermic peaks determined the decomposition of the composites. The samples with a higher amount of recycled carbon content showed a slightly higher temperature and lower heat flow for decomposition.

After hybridization, the melting point temperature increased up to $154.2^{\circ} \mathrm{C}$ for $50 \mathrm{~K} 50 \mathrm{C}$. It is determined that the hybridization with the recycled carbon fiber increased the melting point temperature for all the specimens. Also, the decomposition temperature of the hybrid composites occurred at a higher temperature as compared to the kenaf/cardanol biocomposites. Therefore, in agreement with TGA results, the presence of carbon fiber improved the thermal stability of the kenaf/cardanol composites. 
TABLE 2: Thermal degradation characteristics of hybrid composites.

\begin{tabular}{|c|c|c|c|c|}
\hline Specimen & $\begin{array}{l}\text { Initial degradation }\left({ }^{\circ} \mathrm{C}\right) \\
\text { (weight loss percentage) }\end{array}$ & $\begin{array}{l}\text { Second degradation }\left({ }^{\circ} \mathrm{C} \text { ) }\right. \\
\text { (weight loss percentage) }\end{array}$ & $\begin{array}{c}\text { Final degradation }\left({ }^{\circ} \mathrm{C}\right) \\
\text { (weight loss percentage) }\end{array}$ & Residue content (\%) \\
\hline $100 \mathrm{CL}$ & $430.09(43.04)$ & - & - & 50.43 \\
\hline $50 \mathrm{~K}$ & $286.99(33.5)$ & $392.93(26.86)$ & - & 31.99 \\
\hline $30 \mathrm{~K} 70 \mathrm{C}$ & $277.88(12.05)$ & $435.75(21.78)$ & $629.65(9.55)$ & 52.62 \\
\hline $50 \mathrm{~K} 50 \mathrm{C}$ & $279.55(16.93)$ & 400.89 (19.75) & $618.01(5.94)$ & 52.73 \\
\hline $70 \mathrm{~K} 30 \mathrm{C}$ & $287.59(24.71)$ & $395.65(23.11)$ & $608.82(4.9)$ & 42.5 \\
\hline
\end{tabular}

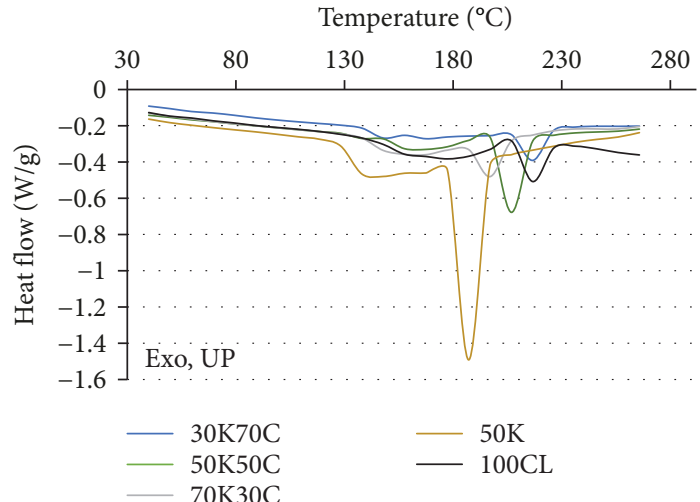

FIGURE 4: DSC of the hybrid composites.

TABLE 3: Melting point and decomposition peak temperature.

\begin{tabular}{lcc}
\hline Specimen & Melting temperature $\left({ }^{\circ} \mathrm{C}\right)$ & $\begin{array}{c}\text { Decomposition } \\
\text { temperature }\left({ }^{\circ} \mathrm{C}\right)\end{array}$ \\
\hline $100 \mathrm{CL}$ & 157.06 & 217.70 \\
$50 \mathrm{~K}$ & 140.63 & 187.50 \\
$30 \mathrm{~K} 70 \mathrm{C}$ & 147.48 & 216.27 \\
$50 \mathrm{~K} 50 \mathrm{C}$ & 154.20 & 209.38 \\
$70 \mathrm{~K} 30 \mathrm{C}$ & 144.92 & 194.04 \\
\hline
\end{tabular}

3.3. Dynamic Mechanical Analysis (DMA). Dynamic mechanical analysis (DMA) was conducted to study the storage modulus and $\tan \delta$ of the specimens with respect to hybridization. The storage modulus illustrated three regions starting with the glassy region, followed by the transition region, and finally the rubbery region [21].

In the first region, the composite structure is rigid and the components are motionless and packed tightly in their place, which leads to the high storage modulus, while in the second region, that is, the glass transition phase, the increment in heat causes the mobility of the components and the storage modulus drops as the temperature goes above the glass transition temperature. From this point, the composite enters the rubbery region in which the components are highly mobile and the structure of the composite is no longer rigid [22, 23].

The storage modulus of the specimen was derived from DMA and is presented in Figure $5 . \tan \delta$ is also presented in Figure 6, which shows the tangent of the phase angle.

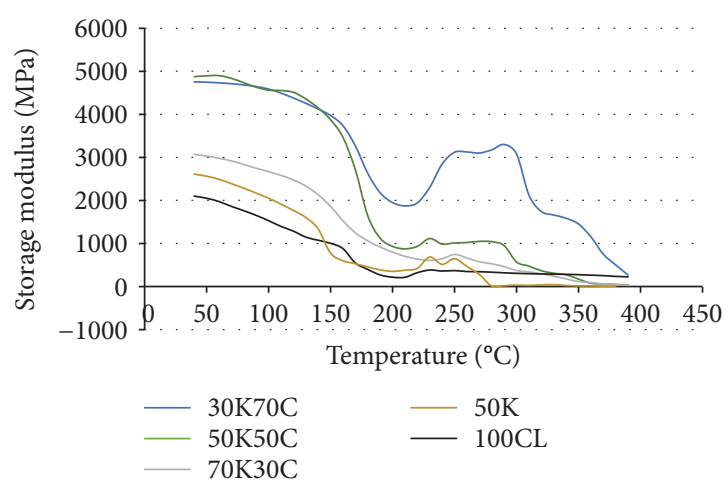

Figure 5: Storage modulus of the hybrid composites (MPa).

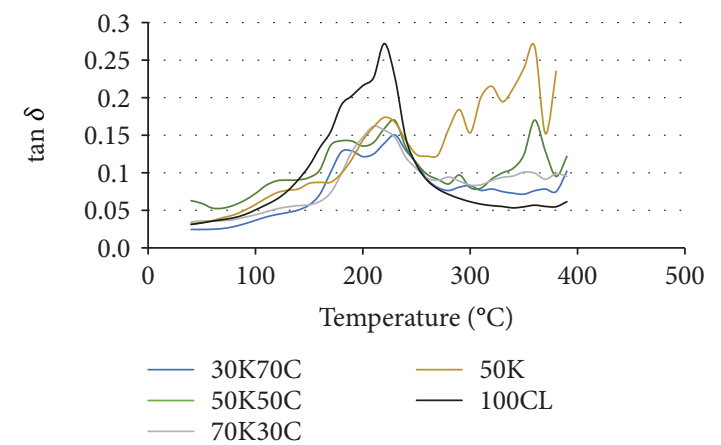

FIgURE 6: $\tan \delta$ of the hybrid composites.

Figure 5 illustrates the decrement of storage modulus with the increment of temperature for all specimens as the storage modulus drops dramatically when the specimen is exposed to the heat. Besides, it was observed that the glassy region is broader than the rubbery plateau which indicated the brittleness of the specimen. It was also shown that at $40^{\circ} \mathrm{C}$, for all of the specimens, the storage modulus was higher than the storage modulus of cardanol indicating the brittle property of cardanol.

Another observation is that with the increment of the recycled carbon content in the composite, the storage modulus increased; for instance, for $30 \mathrm{~K} 70 \mathrm{C}$, the storage modulus drop is much smaller than all the other specimens and the drop increases with the increment of kenaf fiber. Besides, it was determined previously that the storage 
TABLE 4: Flammability results of recycled carbon/kenaf/cardanol hybrid biocomposites.

\begin{tabular}{lccc}
\hline Sample & $\begin{array}{c}\text { Horizontal UL 90 } \\
\text { burning rate }(\mathrm{mm} / \mathrm{s})\end{array}$ & $\begin{array}{c}\text { Flaming } \\
\text { drops }\end{array}$ & $\begin{array}{c}\text { Classifications in } \\
\text { vertical UL 90 }\end{array}$ \\
\hline 100CL & 0 & No & V-0 \\
$50 \mathrm{~K}$ & 1.3 & No & $\mathrm{V}-0$ \\
$30 \mathrm{~K} 70 \mathrm{C}$ & 0.76 & No & $\mathrm{V}-0$ \\
$50 \mathrm{~K} 50 \mathrm{C}$ & 1.18 & No & $\mathrm{V}-0$ \\
$70 \mathrm{~K} 30 \mathrm{C}$ & 1.5 & No & $\mathrm{V}-0$ \\
\hline
\end{tabular}

modulus of the pulp fiber/PLA increased with the increment of fiber loading [24].

At around $250^{\circ} \mathrm{C}$, there was an increment in the storage modulus; this is because, in this region, the specimens were in the rubbery plateau and the increment in the storage modulus was due to the enhancement in the cross-link density [25]. The author suggested that this increment occurred because the polymer underwent intermolecular cross-linking [26]. Besides, the increment in the rubbery plateau indicated that kenaf fiber has an important role in the elastic property of cardanol. The storage modulus of the composites decreased with the temperature indicating that the glass transition occurred before $220^{\circ} \mathrm{C}$. A comparison between the results of storage modulus for hybrid composites and original kenaf/cardanol composites showed that the hybridization improved the storage modulus, especially for specimens with higher amounts of carbon content [27].

From Figure 6, it can be observed that the peak of $\tan \delta$ for cardanol was higher than all other specimens, which also agreed with the previous results that showed cardanol had a lower damping property and was more brittle than the kenaf/cardanol composites; the shift of $\tan \delta$ and the reduction of the absolute value indicate the interaction between kenaf and cardanol which enhanced the mechanical properties of the kenaf/cardanol composites [28]. It was also observed that the specimen with a higher fiber volume fraction showed the lower $\tan \delta$ and higher damping property.

3.4. Flammability UL $90 \mathrm{HB}$. The calculated burning rate is illustrated in Table 4. For almost all of the specimens, the flame was extinguished right after separating the applied flame from the specimen and the specimens did not drop or melt. All the values for the burning rate were less than $40 \mathrm{~mm} / \mathrm{s}$, which means that according to the UL $90 \mathrm{HB}$ standard, the cardanol fire retardancy did not decrease with the composition since the flame was extinguished before reaching the first mark at $25 \mathrm{~mm}$ for all specimens. Besides, no smoke generation was observed for any of the specimens.

Therefore, all specimens were considered fire retardant as expected [29] and the presence of the kenaf fiber did not change the fire retardancy property of cardanol. Although, in agreement with TGA, the presence of kenaf fiber could reduce the thermal stability, it is observed that the burning rate of almost all samples is higher than that of cardanol, but still according to the standard since the flames of all specimens were extinguished before reaching the first mark on the specimen; they are all considered in the same class as
$\mathrm{V}-0$. This class means the specimens have a good flammability property probably due to the char development and heat transfer reduction from the flame to the composite by the protection of the polymer from oxygen [30].

\section{Conclusion}

Thermal characterizations of the specimens indicate that cardanol improved the thermal stability of kenaf and hybridization with recycled carbon also further improved the thermal stability of the specimens. The flammability UL $90 \mathrm{HB}$ test determines the flame retardancy property of all specimens.

It was observed that the peak of $\tan \delta$ for cardanol was higher than all the other specimens which also agreed with the previous results that showed cardanol had a lower damping property and was more brittle than the kenaf/cardanol composites; the shift of $\tan \delta$ and the reduction of the absolute value indicate the interaction between kenaf and cardanol which enhanced the mechanical properties of the kenaf/cardanol composites. It was also observed that the specimen with higher fiber volume fraction showed the lower $\tan \delta$ and higher damping property.

\section{Data Availability}

The raw/processed data required to reproduce these findings cannot be shared at this time as the data also forms part of an ongoing study.

\section{Conflicts of Interest}

The authors declare that they have no conflicts of interest.

\section{Acknowledgments}

The authors would like to thank the MOSTI grant (Vote No. 5450760) for providing support to this research experiment and all the very kind and helpful staff of the Institute of Tropical Forestry and Forest Products (INTROP), University Putra Malaysia (UPM).

\section{References}

[1] H. Nady, M. M. El-Rabiei, and G. M. Abd El-Hafez, "Electrochemical oxidation behavior of some hazardous phenolic compounds in acidic solution," Egyptian Journal of Petroleum, vol. 26, no. 3, pp. 669-678, 2017.

[2] A. Jabbar, J. Militký, B. Madhukar Kale, S. Rwawiire, Y. Nawab, and V. Baheti, "Modeling and analysis of the creep behavior of jute/green epoxy composites incorporated with chemically treated pulverized nano/micro jute fibers," Industrial Crops and Products, vol. 84, pp. 230-240, 2016.

[3] R. Yahaya, S. M. Sapuan, M. Jawaid, Z. Leman, and E. S. Zainudin, "Effect of layering sequence and chemical treatment on the mechanical properties of woven kenaf-aramid hybrid laminated composites," Materials \& Design, vol. 67, pp. 173-179, 2015.

[4] S. Job, "Composite recycling-summary of recent research and development," Knowledge Transfer Network-Materials, vol. 1, pp. 1-25, 2010. 
[5] S. J. Pickering, "Recycling technologies for thermoset composite materials-current status," Composites Part A: Applied Science and Manufacturing, vol. 37, no. 8, pp. 1206-1215, 2006.

[6] T. Suzuki and J. Takahashi, "Prediction of energy intensity of carbon fiber reinforced plastics for mass-produced passenger cars," in 9th Japan International SAMPE symposia, pp. 14-19, Tokyo Big Sight, 2005.

[7] A. Maffezzoli, E. Calò, S. Zurlo, G. Mele, A. Tarzia, and C. Stifani, "Cardanol based matrix biocomposites reinforced with natural fibres," Composites Science and Technology, vol. 64, no. 6, pp. 839-845, 2004.

[8] R. Srivastava and D. Srivastava, "Mechanical, chemical, and curing characteristics of cardanol-furfural-based novolac resin for application in green coatings," Journal of Coatings Technology and Research, vol. 12, no. 2, pp. 303-311, 2015.

[9] A. K. Mohanty, A. Khan Mubarak, S. Sahoo, and G. Hinrichsen, "Effect of chemical modification on the performance of biodegradable jute yarn-Biopol ${ }^{\circledR}$ composites," Journal of Materials Science, vol. 35, no. 10, pp. 2589-2595, 2000.

[10] A. K. Mohanty, M. Misra, and G. Hinrichsen, "Biofibres, biodegradable polymers and biocomposites: an overview," Macromolecular Materials and Engineering, vol. 276-277, no. 1, pp. 1-24, 2000.

[11] H. P. S. Abdul Khalil, H. M. Fizree, M. Jawaid, and S. Alattas Omar, "Preparation and characterization of nanostructured materials from oil palm ash: a bio agricultural waste from oil palm mill," BioResources, vol. 6, no. 4, pp. 4537-4546, 2011.

[12] C. Alves, P. M. C. Ferrão, A. J. Silva et al., "Ecodesign of automotive components making use of natural jute fiber composites," Journal of Cleaner Production, vol. 18, no. 4, pp. 313-327, 2010.

[13] H. Ku, F. Cardona, J. Ball, W. Jacobson, and M. Trada, "Relationship between electrical and mechanical loss tangents of SLG reinforced phenolic composites: pilot study," Journal of Composite Materials, vol. 42, no. 19, pp. 2083-2095, 2008.

[14] C. P. Reghunadhan Nair, "Advances in addition-cure phenolic resins," Progress in Polymer Science, vol. 29, no. 5, pp. 401-498, 2004.

[15] S. A. Brent, Plastics: materials and processing, Pearson Prentice Hall, 2006

[16] J. L. Clarke, Structural design of polymer composites: Eurocomp design code and background document, E \& FN Spon, 2005.

[17] E. Ferri and D. Talentino, "Bio-resins from cashew nutshell oil," Reinforced Plastics, vol. 55, no. 3, pp. 29-31, 2011.

[18] Y.-H. Zhao, Y.-F. Zhang, S.-L. Bai, and X.-W. Yuan, "Carbon fibre/graphene foam/polymer composites with enhanced mechanical and thermal properties," Composites Part B: Engineering, vol. 94, pp. 102-108, 2016.

[19] G. Dolo, J. Férec, D. Cartié, Y. Grohens, and G. Ausias, "Model for thermal degradation of carbon fiber filled poly (ether ether ketone)," Polymer Degradation and Stability, vol. 143, pp. 20-25, 2017.

[20] P. Tadini, N. Grange, K. Chetehouna, N. Gascoin, S. Senave, and I. Reynaud, "Thermal degradation analysis of innovative PEKK-based carbon composites for high-temperature aeronautical components," Aerospace Science and Technology, vol. 65, pp. 106-116, 2017.

[21] N. Saba, M. Jawaid, O. Y. Alothman, and M. T. Paridah, "A review on dynamic mechanical properties of natural fibre reinforced polymer composites," Construction and Building Materials, vol. 106, pp. 149-159, 2016.
[22] M. Jawaid and H. P. S. Abdul Khalil, "Effect of layering pattern on the dynamic mechanical properties and thermal degradation of oil palm jute fibers reinforced epoxy hybrid composite," BioResources, vol. 6, no. 3, pp. 2309-2322, 2011.

[23] J. Maya, F. Bejoy, and T. Sabu, "Dynamical mechanical analysis of sisal/oil palm hybrid fiber-reinforced natural rubber composites," Polymer Composites, vol. 27, no. 6, pp. 671-680, 2006.

[24] Y. Du, T. Wu, N. Yan, M. T. Kortschot, and R. Farnood, "Fabrication and characterization of fully biodegradable natural fiber-reinforced poly(lactic acid) composites," Composites Part B: Engineering, vol. 56, pp. 717-723, 2014.

[25] P. Deepalekshmi and T. Sabu, Non-Linear Viscoelasticity of Rubber Composites and Nanocomposites: Influence of Filler Geometry and Size in Different Length Scales, Springer, Technology \& Engineering, 2014.

[26] W. Herrera-Kao and M. Aguilar-Vega, "Storage modulus changes with temperature in poly(vinyl alcohol), PVA,/poly(acrylic acid), PAA, blends," Polymer Bulletin, vol. 42, no. 4, pp. 449-456, 1999.

[27] G. Cicala, E. Pergolizzi, F. Piscopo, D. Carbone, and G. Recca, "Hybrid composites manufactured by resin infusion with a fully recyclable bioepoxy resin," Composites Part B: Engineering, vol. 132, pp. 69-76, 2018.

[28] T. Nishino, K. Hirao, M. Kotera, K. Nakamae, and H. Inagaki, "Kenaf reinforced biodegradable composite," Composites Science and Technology, vol. 63, no. 9, pp. 1281-1286, 2003.

[29] M. E. Mngomezulu, M. J. John, V. Jacobs, and A. S. Luyt, "Review on flammability of biofibres and biocomposites," Carbohydrate Polymers, vol. 111, pp. 149-182, 2014.

[30] E. Netnapa, M. Mariatti, Z. A. A. Hamid, M. Todo, and L. Banhan, "Dielectric breakdown strength and flammability properties of flame retardant filler/PLLA-PLA microsphere/kenaf fiber composites," Procedia Chemistry, vol. 19, pp. 290-296, 2016. 


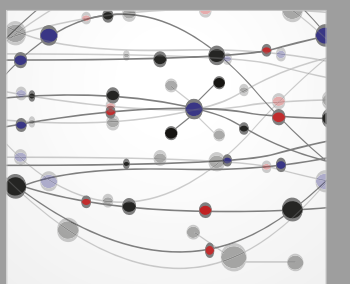

The Scientific World Journal
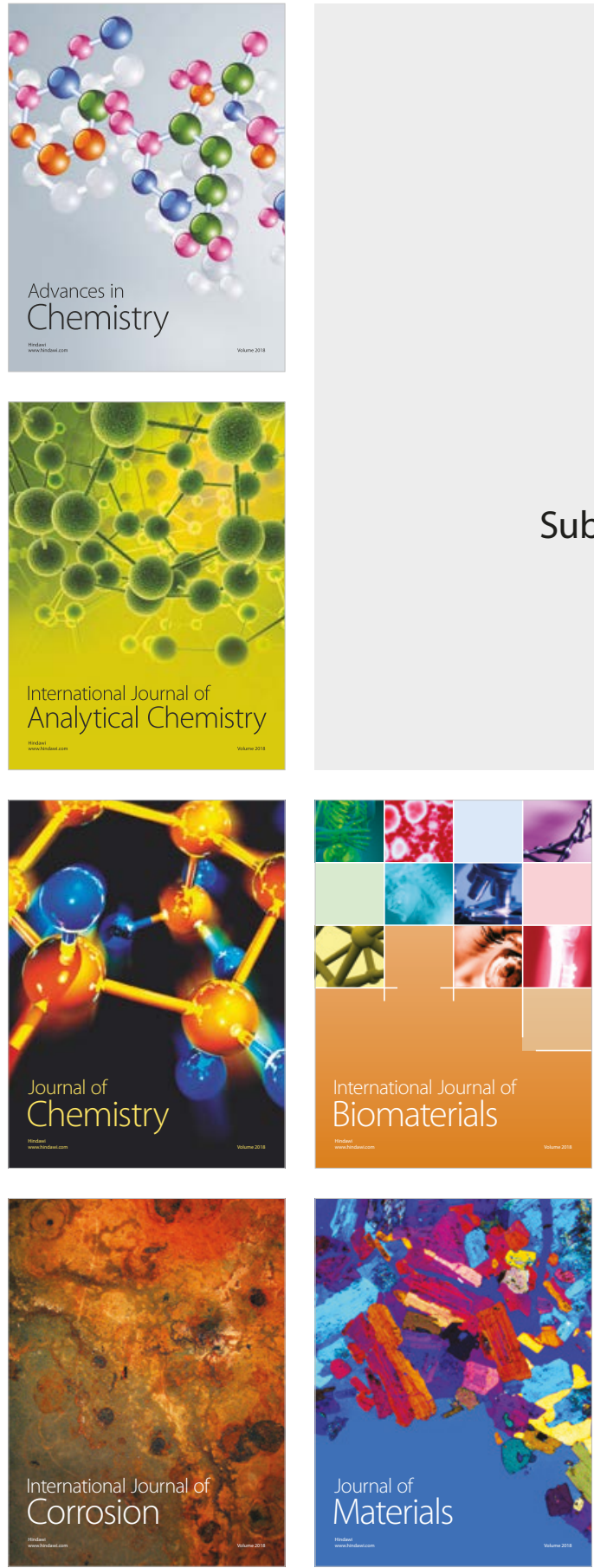

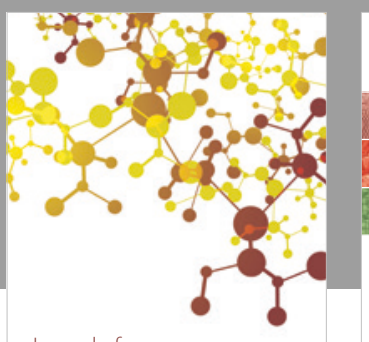

Journal of

Applied Chemistry
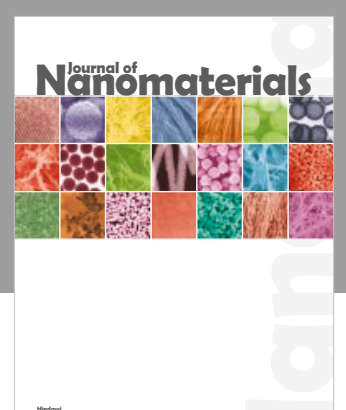

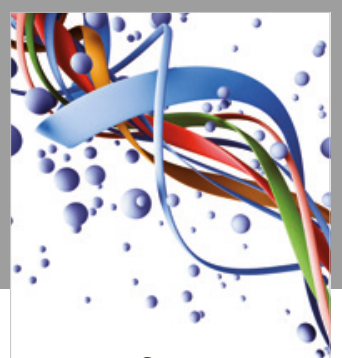

Scientifica

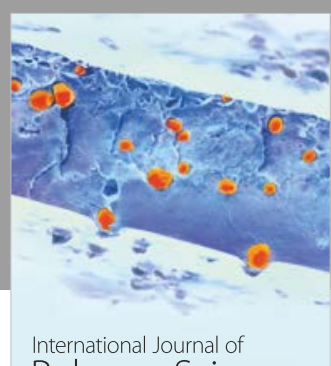

Polymer Science

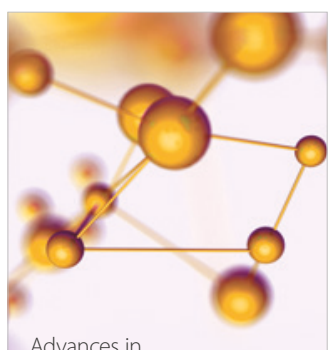

Physical Chemistry
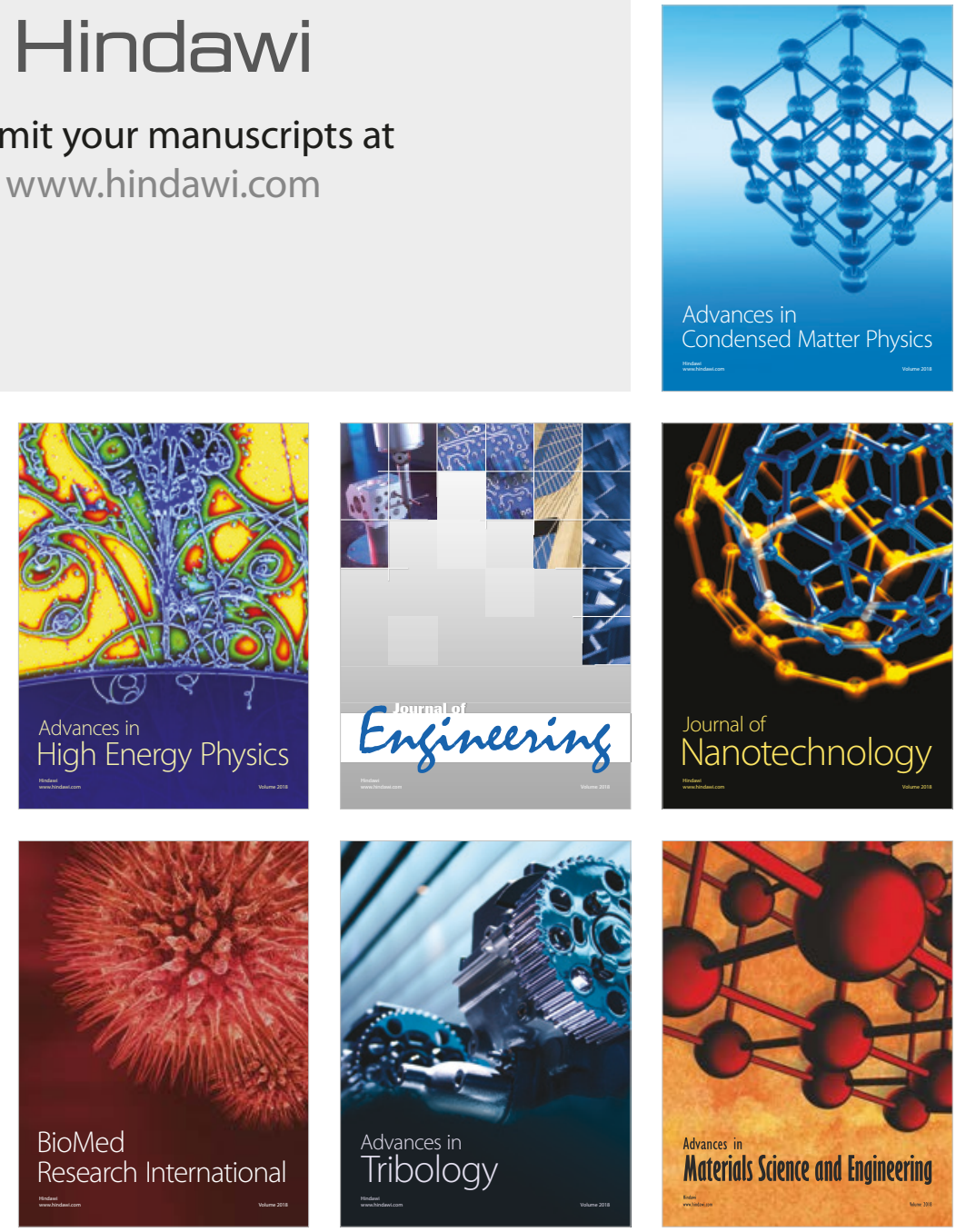